\title{
CUBA, PUNTO DE (DES)ENCUENTRO DE LA CULTURA OCCIDENTAL EN LA NARRATIVA DE LEONARDO PADURA
}

\author{
POR \\ ÁNGel EsteBAn \\ Universidad de Granada
}

La narrativa de Leonardo Padura ha seguido las pautas diacrónicas que le ha ofrecido la evolución de la cultura occidental desde su primera novela, Fiebre de caballos, escrita en 1983-1984 y publicada en 1988, hasta laúltima, Herejes, de 2013. También se observa en el cubano una adecuación a los ritmos de la historia de Cuba y de la personal, desde aquellos ochenta en los que, antes de la condena a muerte de Ochoa y De la Guardia y antes de los funerales de la Mamá Grande (la Unión Soviética), todavía quedaban románticos que esperaban un futuro mejor para la isla en el contexto de la economía comunista y la política de férrea dictadura, para la cual, la lucha contra el enemigo y su bloqueo justificaba la represión y la total ausencia de libertad de expresión, de asociación, de culto y de participación ciudadana en la vida política. Por eso, Fiebre de caballos es una historia de amor sin crítica social, un Bildungsroman de un adolescente que se enamora, y vive en una sociedad cuyos basamentos no se cuestionan. El universo es cubano y cerrado sobre sí mismo, sobre "la isla que se repite". Se trata más bien de una reflexión sobre el tiempo, al que se mira con la nostalgia y la resignación del que sabe que se le escapa y no volverá. En la última edición de la novela, de 2014, Padura explica en el prólogo esas circunstancias diatópicas y diacrónicas o, como diría Bajtin, cronotópicas, y aclara que quienes la lean ahora "podrían concluir que mis personajes de entonces y sus conflictos eran complacientes con la realidad. Y puede ser una apreciación cierta; pero solo si se entiende que esa era su realidad, esos sus conflictos" (Fiebre 14). De esa primera tentativa hasta su última entrega, Padura ha politizado cada vez más su actividad escrituraria, y en los noventa se ha centrado en la situación caótica y sin salida de la isla, para dejar paso en el nuevo siglo y milenio a una narrativa que se libera del círculo cerrado de "lo cubano" y conecta la identidad nacional con fenómenos culturales, sociales, políticos e históricos que sacan a Cuba del narcisismo lastimero y quejumbroso de las miserias sufridas en el Periodo Especial. En las novelas del presente siglo, Cuba sigue siendo el centro de atención pero se encuentra permanentemente conectada con un mundo que está fuera de ella, que lo complementa, que lo explica incluso mejor que ella a sí misma, y que le da presencia 
en un mapa que antaño era solo un lagarto verde y en el que han aparecido, por fin, los océanos, los continentes. En su reciente recopilación de ensayos, Yo quisiera ser Paul Auster (2015), Padura da cuenta de lo que supuso, no solo para él sino para toda su generación, el hecho de que en los noventa la narrativa se centrara nada más, obsesivamente, en los propios desengaños y en las manifiestas carencias:

En medio de esa nueva circunstancia nacional [el periodo especial], tal vez el mayor error de esta literatura más desenfadada o desencantada o con intenciones críticas haya sido su falta (o la incapacidad de algunos de sus creadores) de una perspectiva más universal, es decir, menos localista. La insistencia en determinados mundos sociales, personajes representativos, problemáticas específicas y modos expresivos que se tornaron repetitivos, hizo que una parte notable de esta literatura se encallara en lo inmediato, en las tan peculiares peculiaridades cubanas. (Yo quisiera 18)

Es cierto que parece estar hablando de otros escritores y no de sí mismo, pero dado su cambio de orientación a comienzos del nuevo siglo, hacia una nueva amplitud de miras, que se matiza hasta el extremo de que Mario Conde deja de ser un policía enfangado en las miserias más repugnantes de La Habana y se convierte en escritor y vendedor de libros, es claro que Padura toma nota de lo que observa y rectifica el rumbo. Esta derivación se sitúa en el ámbito de actuación de la mayoría de los escritores latinoamericanos de los últimos años, que han abandonado la necesidad de escribir sobre el propio país, desde el propio país y en el contexto de la identidad latinoamericana o nacional. Es claro que Padura nunca ha roto los lazos con las temáticas cubanas, ni ha dejado de residir en su país, por lo que no es un sujeto desterritorializado ni esencialmente globalizado pero, en una posición intermedia a la de la mayoría de los miembros de la siguiente generación (Edmundo Paz Soldán, Fernando Iwasaki, Jorge Eduardo Benavides, Jorge Volpi, José Manuel Prieto, etc.), ha combinado la omnipresencia del origen con la apertura a otras culturas.

La producción literaria de Padura en los años noventa se centró en la serie de "Las cuatro estaciones", donde el policía antihéroe Mario Conde trataba de resolver crímenes en la Cuba de los márgenes, destruida y sin horizonte, abocada a la desesperanza. Ese ciclo, que duró toda la década (1991, 1994, 1997 y 1998), parecía cerrado cuando se publicó la novela de la cuarta estación, Paisaje de otoño, de 1998, pero después han aparecido cuatro entregas más en las que Mario Conde vuelve a ser protagonista. La más cercana al estilo y propósitos de la tetralogía es La cola de la serpiente, publicada en 2011. Aunque está muy alejada en el tiempo de publicación respecto a las de los noventa, su entorno es más parecido al de ellas porque se trata de un relato que fue escrito en 1998, desarrollado más adelante, hasta una primera edición como noveleta en 2001, y la definitiva (corregida y aumentada) diez años más tarde. En esta novela existe, para aludir a ella desde la perspectiva que planteamos, una trama volcada en

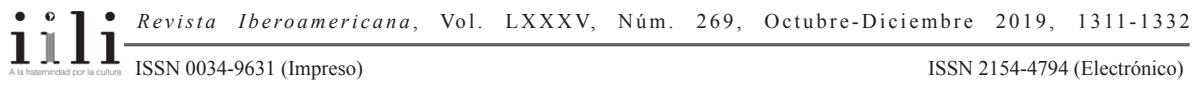


La Habana, que continúa siendo una ciudad oscura y hostil, centrada en lo cubano y en la crisis que comenzó en los noventa, ahora desde la mirada de la comunidad china que tiene, como en la mayoría de las grandes ciudades, su barrio, y que en la capital cubana está casi destruido, prácticamente en ruinas. Por ello, su fecha de publicación definitiva (2011) es engañosa, al constituir una reelaboración de un material más acorde con las preocupaciones manifestadas en las obras de los noventa.

Por tanto, las novelas que nos van a interesar en nuestro propósito serán todas las publicadas en el presente siglo excepto La cola de la serpiente. De todas ellas, hay una que vuelve al planteamiento general de las de los noventa, La neblina del ayer (2005), es decir, un ambiente cerrado sobre sí mismo, en La Habana, y con una carga crítica de elevadas dimensiones. Sin embargo, hay algunas novedades que tratan tímidamente de abrir ese círculo o vorágine narcisista. Conde ya no es una policía que trabaja en casos en los que se puede rastrear la omnipresencia de la ciudad decrépita. De hecho, ya dimitió como tal en las últimas páginas de Paisaje de otoño, para tratar de convertirse en escritor de ficción, y en La neblina del ayer lo encontramos convertido en una especie de empresario que compra y vende libros por toda la ciudad, visitando casas y bibliotecas. El mundo del arte, que es universal, simbolizado en la literatura, y también en la música, remite a una realidad espiritual que rebasa los contornos de la isla. Asimismo, el recurso a la Historia, que será frecuente en toda la producción narrativa del presente siglo, añade una perspectiva descentralizadora, al combinar detalles del pasado que invitan a negociar juicios sobre el presente, en lugar de emitir quejas por la situación a la que hay que enfrentarse. El verso del bolero que da título a la novela representa el conato de la globalización, ya que se trata de una canción compuesta por argentinos y cantada por decenas de intérpretes de todos los países de habla hispana, que ha sido traducida a varios idiomas y cantada por artistas famosos en varias lenguas pero, a la vez, da estructura a la obra, que tiene una Cara A y una Cara B, como los antiguos vinilos. Partiendo de esa primera apertura, en la novela caben comentarios acerca de la música extranjera que estuvo prohibida en Cuba en los años sesenta y setenta, que se propone además como contrapunto a la música oficial de la Revolución por aquellos años, la "Nueva Trova Cubana", con sus dos máximos exponentes, Silvio Rodríguez y Pablo Milanés. El círculo de amistades de Conde no recuerda nada de estos últimos, pero sí se refiere con asiduidad a Los Beatles, Chicago, Los Creedence, y algunos latinos no cubanos como Fórmula V o Los Pasos. Esas elecciones pueden tener un marcado sesgo político, que apuntala la crítica al presente (2003, el momento en el que se desarrolla la acción), mediante el recuerdo ominoso del pasado represivo. Así lo ha visto Néstor Ponce:

La ausencia de alusiones a dicho movimiento [la "Nueva Trova"] repercute en un texto en que los boleristas, los rockeros e incluso los jazzistas son objeto de continuas menciones. El silencio textual corresponde a los silencios de la música, se prolonga

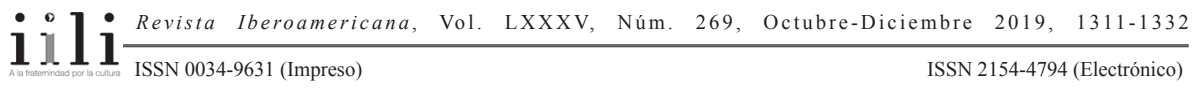


en el silencio político: si Pablo Milanés o Silvio Rodríguez no son citados, tampoco lo son las principales figuras de la Revolución. ("Historia, memoria" s/p)

Algo parecido ocurre con el constante recurso a la literatura. En primer lugar, el nuevo oficio de Conde nada tiene que ver con el servicio a la patria que suponía su anterior dedicación. Es más bien un asunto de cultura, que navega peligrosamente en las aguas del negocio privado imposible en la isla, y que se instala además en un territorio pantanoso para el que lo acomete en el universo de las dictaduras. En segundo lugar, Conde y sus amigos se refieren constantemente a la época en la que los escritores dejaron de ser intocables y se convirtieron en el blanco más vulnerable del ejercicio absoluto del poder. El caso Padilla y el quinquenio gris, es decir, desde 1968 hasta 1976, marcan las pautas definitivas de lo que va a ser la posición oficial con respecto a la literatura y el arte. Aquel "Dentro de la revolución, todo; fuera de la revolución, nada" de 1961 cobró triste y radical realidad al final de esa década y comienzos de la siguiente. Valga como botón de muestra el discurso de Fidel Castro en la clausura del Primer Congreso Nacional de Educación y Cultura, de abril de 1971, días después de la detención y la tortura de Padilla. Castro criticó duramente a los intelectuales burgueses, y sobre todo a aquellos pseudoizquierdistas que preferían frecuentar los salones de París que arrimar el hombro con su trabajo, su esfuerzo e incluso con su participación en la lucha armada. Y concluía:

Nosotros, un pueblo revolucionario en un proceso revolucionario, valoramos las creaciones culturales y artísticas en función de la utilidad para el pueblo, en función de lo que aporten al hombre, en función de lo que aporten a la reivindicación del hombre, a la liberación del hombre, a la felicidad del hombre.

Nuestra valoración es política. No puede haber valor estético sin contenido humano. No puede haber valor estético contra el hombre. No puede haber valor estético contra la justicia, contra el bienestar, contra la liberación, contra la felicidad del hombre. ¡No puede haberlo!

Para un burgués cualquier cosa puede ser un valor estético, que lo entretenga, que lo divierta, que lo ayude a entretener sus ocios y sus aburrimientos de vago y de parásito improductivo (APLAUSOS). Pero esa no puede ser la valoración para un trabajador, para un revolucionario, para un comunista. Y no tenemos que tener ningún temor a expresar con toda claridad estas ideas. ${ }^{1}$

1 El texto íntegro del discurso, en el que se incluyen además los momentos en los que el público se ríe o aplaude, se encuentra en http://www.cuba.cu/gobierno/discursos/1971/esp/f300471e.html. Visitado el 19 de mayo de 2015. 
Por eso, el Congreso tuvo que concretar hasta los detalles más insignificantes sobre cómo debería "hacerse" la cultura en Cuba a partir de entonces. Una de sus conclusiones fue que "los medios culturales no pueden servir de marco a la proliferación de falsos intelectuales que pretenden convertir el esnobismo, la extravagancia, el homosexualismo, y demás aberraciones sociales, en expresión del arte revolucionario, alejados de las masas y del espíritu de nuestra revolución". " "Demás aberraciones" como los temas religiosos, que ya no deberían volver a tocarse por los artistas e intelectuales, la música rock o, en general, música en el idioma del enemigo (Los Beatles y demás grupos anglosajones fueron prohibidos), e incluso la manera de vestir de los jóvenes, que deberían optar por la guayabera, en lugar de las modas que el enemigo estaba implantando en todo occidente. Así, no es un detalle banal que Padura haya elegido esa época para su reflexión especular con el presente, haciendo pública además la nueva faceta de este cambiado Mario Conde, que ha dejado de ser un policía socarrón y se ha convertido en un culto vendedor de libros y en aspirante a escritor refinado, cuyo punto de mira se ha elevado de lo marginal habanero hasta los confines de la literatura universal, libre, y la música que traspasa cualquier tipo de frontera.

A pesar de esa evolución en La neblina del ayer en comparación con el espacio habanero cerrado de los noventa, son el resto de las novelas del siglo XXI las que proponen más explícitamente una reflexión sobre la historia, la política y la cultura cubanas en un contexto más universal: Adiós, Hemingway (2001), La novela de mi vida (2002), El hombre que amaba a los perros (2009) y Herejes (2013). En cada una de ellas hay un momento crucial de la historia occidental que se cruza con la historia de Cuba, y convierte a la isla en protagonista vicaria de civilización contemporánea. Y, a la vez, esa confluencia sirve para el autoesclarecimiento cubano. No es común que un escritor cubano acuda a agentes externos a la isla para indagar en la identidad cubana. Los grandes teóricos de la identidad cubana han seguido las huellas de Martí en Nuestra América (1891), para quien el gobierno de un país debe nacer del país, y para explicar a un país hay que hacerlo con el lenguaje y los elementos propios del país. Asimismo, para que un país se desarrolle, debe buscarse el progreso alrededor de los sujetos y relaciones de los que conforman el país, sin imitar fórmulas foráneas que, quizá, han sido muy útiles allá donde se han implementado, pero no tienen por qué funcionar igual en nuestra tierra. Hasta tal punto llegaba la confianza de Martí en lo autóctono, que aseguró, en forma de sentencia: "El vino, de plátano; y si sale agrio, ¡es nuestro vino!” (Obras completas VI, 15). A partir de Martí, la gran mayoría de los intelectuales han estudiado la cubanía partiendo de lo autóctono y quedándose en ello. Lezama Lima, para inaugurar el estudio sobre la poesía cubana afirmó que la "nuestra

2 Las conclusiones fueron publicadas en las primeras páginas del ejemplar del 1 de mayo, día siguiente a la clausura del congreso, de la revista Unión. En concreto, estas líneas son de la página 7. 
isla comienza la historia dentro de la poesía" (Lezama Lima, Esteban y Salvador I, 3). La tesis de Lezama lleva la idea martiana al comienzo de la historia: la isla se funda dentro del mundo de la poesía, que ya es cifra de la cubanía, y ella define al cubano, sin hacer mención siquiera al sustrato español. Cintio Vitier, en Lo cubano en la poesía (1958), no dista mucho de la tesis de su maestro Lezama, y un ensayista tan brillante y lúcido como Fernando Ortiz no duda en emular a Martí utilizando productos de la tierra para ubicar la identidad: el tabaco y el azúcar definen al cubano, en sus cualidades espirituales, mejor que cualquier otro elemento, porque son los productos más genuinos de la isla y poseen los mismos rasgos que el carácter del cubano.

Con las novelas del siglo XXI, Padura supera esa tendencia y pone al mundo contemporáneo transatlántico a negociar la identidad cubana con la misma isla. En Adiós, Hemingway, Mario Conde comienza su aventura preguntándose en la primera página del relato qué estaba haciendo en Cojímar y cuál era la razón verdadera por la que se encontraba envuelto en aquella investigación, mientras recordaba cómo conoció a Hemingway cuando tenía 5 o 6 años. Y esa reflexión, que es necesidad de autoesclarecimiento, termina en desazón, pues debe aceptar "la maligna evidencia de que debía vivir con más interrogantes que respuestas" (15). Poco más adelante, en la primera conversación con Juan Tenorio, el director del museo de Hemingway, este le habla de los "hemingwayanos cubanos", y se establece la siguiente conversación, sobre la pregunta de Conde acerca del colectivo:

-¿Los hemingwayanos cubanos? ¿Qué es eso, una logia o un partido?

-Ni una cosa ni la otra: somos gentes a las que nos gusta Hemingway. Y hay de todo: escritores, periodistas, maestros y amas de casa y jubilados.

-¿Y qué hacen los hemingwayanos cubanos?

-Pues nada, leer a Hemingway, estudiarlo, hacer coloquios sobre su vida.

-¿Y quién dirige eso?

-Nadie..., bueno, yo un poco organizo a la gente, pero no los dirige nadie.

-Es la fe por la fe, pero sin curas ni secretarios generales. No está mal eso -admitió el Conde, admirado por la existencia de aquella cofradía de crédulos independientes en un tiempo de incrédulos sindicalizados.

-No es fe, no. Es que era un gran escritor y no el ogro que a veces pintan. Y usted, ¿no es hemingwayano?

El Conde debió meditar un instante antes de responder.

-Lo fui, pero devolví el carnet.

- ¿Y es policía o no es policía?

-Tampoco. Es decir, ya tampoco soy policía.

-¿Y entonces qué cosa es? Vaya, si se puede saber.

-Ojalá lo supiera... Por lo pronto estoy seguro de lo que no quiero ser. Y una de las cosas que no quiero ser es policía: he visto demasiada gente volverse hijos de puta cuando su trabajo debía ser joder a los hijos de puta. Además, ¿ha visto usted algo más antiestético que un policía? (23-24) 
La obsesión por el autoesclarecimiento es nítida: un ex policía que aborrece su vida anterior y no sabe lo que es, acuciado por la pregunta acerca de la identidad en el contexto del "ser hemingwayano". Esto ocurre en las novelas del nuevo siglo, pero a la vez existe la posibilidad del camino contrario. ¿Puede la historia de Cuba, individual y colectiva, ofrecer respuestas identitarias al mundo occidental? ¿Es posible que, por encima del ensimismamiento y el ostracismo de la cultura y la sociedad cubanas, existan momentos de la historia en los que los insulares hayan ofrecido pautas de comportamiento o protagonizado procesos que pudieron cambiar el rumbo de la cultura y la civilización occidentales? Padura se lamenta en Yo quisiera ser Paul Auster del deplorable estado de desinformación del escritor y el intelectual cubano que vive en la isla sobre lo que se está escribiendo en otras latitudes, que no es un mal de los años en los que él ha escrito, los noventa y los dos mil, sino de muchas décadas atrás. Incluso aquellos más inquietos, enterados y con posibilidades de cierto contacto con el mundo exterior, tienen una formación y una información aleatorias, dependientes "no de sus necesidades sino de sus posibilidades de comprar o encontrarse con determinados autores y obras que, en ningún caso, se publican o distribuyen en el país" (19). De ahí la necesidad, en los últimos años, de relacionarse con el exterior no solo de una manera física, sino cultural e identitaria. Todo esto nos lleva a plantearnos nuevas preguntas: ¿cuándo y por qué decidió el de Mantilla derivar su narrativa hacia esa apertura? Y, lo más importante, ¿fue una decisión plenamente consciente, o más bien se trató de seguir las pautas que los escritores más jóvenes de Europa y América comenzaban a diseñar? Quizá haya un poco de todo en esa decisión o evolución, pero lo que está claro es que en 2005 ya hacía apología de la "mezcla" como un valor contemporáneo, una implicación muy positiva de nuestro tiempo, como una "celebración de la identidad", que ha ocurrido siempre, pero de modo especial en estos momentos, y que se concreta en la capacidad del hombre "de conocer al otro y, llegado el momento, de mezclarse con el otro, para que nazca lo nuevo, que casi siempre es mejor" (Yo quisiera 177). En el origen de su evolución narrativa personal pudo intervenir una circunstancia aleatoria, no pensada ni decidida conscientemente. Hacia el cambio del siglo y del milenio fue invitado por sus editores brasileños a participar en una serie de publicaciones bajo el título de "Literatura o muerte", en la que debería unir el nombre de algún escritor famoso con el género negro. La elección, dice Padura, fue inmediata, pues con Hemingway ha tenido durante mucho tiempo una relación encarnizada de "amor-odio" (Adiós 10). Enfrentarse a él fue el modo de exorcizar sus demonios, pasando todas sus obsesiones a Mario Conde, quien las soportaría como un enorme fardo durante toda la novela.

El texto funciona en el nivel de las cuentas que el protagonista debe arreglar con el Premio Nobel, pero también desde una mirada más elevada. Hemingway simboliza, en la cultura de los Estados Unidos, un eterno inconformista; tanto, que él mismo terminó con su vida. Por un lado, denota una peculiar actitud en el grupo de la Generación Perdida, por sus polémicas con Faulkner y su literatura absolutamente experiencial, basada en

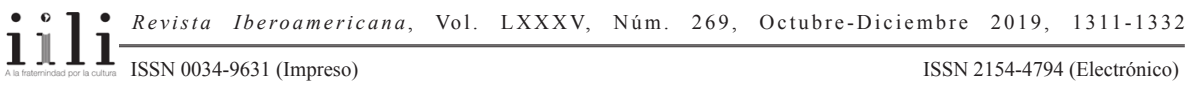


una vida aventurera y arriesgada. Por otro significa, en el contexto de la Revolución, un desafío al imperialismo de su país. Hemingway vivió más de veinte años en Cuba, y aunque en los comienzos de 1959 saludó con optimismo la acción revolucionaria que terminó con la caída del dictador Batista, más tarde sufrió las consecuencias del acoso a la propiedad privada por parte del nuevo gobierno. No obstante, para Cuba es un ejemplo de un estadounidense que entendió las ventajas de la vida apacible en un pequeño pueblo de pescadores frente a las servidumbres del desarrollo del norte. Cuba sería, en ese sentido, la toma de conciencia de la posibilidad de "otro tipo de vida", en contacto con la naturaleza. El viejo y el mar (1952) sería la cifra de esa propuesta: el hombre no lucha contra un estado o una sociedad que oprimen, en una tarea descomunal e inútil, sino contra la misma naturaleza, en un enfrentamiento noble que posibilita la heroicidad. Demostrar, entonces, que Hemingway no mató al hombre que estaba enterrado en su finca es también recuperarlo para esa visión idílica del mundo natural alejado de los centros. En eso abunda el artículo de Padura dedicado a los desencuentros de Hemingway con Hoover y con el FBI, agencia para la que el Nobel trabajaba desde Cuba, pero con la que nunca llegó a tener una relación coherente con su posición dentro de ella, porque era muy crítico con sus procedimientos y fines. Padura sugiere además que Hemingway estaba escribiendo un libro sobre el FBI en el que se explayaba describiendo sus métodos de presión, vigilancia, ocultamiento de datos y chantaje (Yo quisiera 225), y que Hoover hizo todo lo posible por propagar la imagen de un Hemingway borracho, indisciplinado, inútil, patético y proclive a ideas comunistas (225). El Nobel estadounidense, que aceptó trabajar en el FBI para informar sobre actividades de la Falange Española y nazis radicados en la isla, llegó incluso a estar involucrado con el famoso suceso del barco lleno de judíos que no pudo dejar a sus pasajeros en La Habana y que ha inspirado la novela Herejes, de Padura. No parece, por tanto, muy aleatoria la elección de Hemingway para una novela de encargo, cuando el de Mantilla se está planteando salir del mundo cerrado de Cuba y valorar esas interacciones que amplifican la visión de una isla que posee un protagonismo primordial en ciertos episodios cruciales de la historia occidental. En las cuatro novelas que estamos considerando, política y literatura (o arte) son los dos ejes que posibilitan esa mirada, la de un protagonismo histórico que termina para siempre con el tópico de Cuba como una isla donde nunca pasa nada, donde el tiempo se ha detenido y solo cabe en las imágenes de sus costas paradisiacas, sus palmeras y sus mulatas.

En la siguiente entrega, La novela de mi vida, nuevamente confluyen historia, política y literatura en el encuentro de Cuba con el mundo occidental. La mayoría de los muchos críticos que han escrito sobre ella concuerdan en el propósito identitario: Padura trata de indagar en la cubanía a través de la figura del primer gran escritor romántico cubano, José María Heredia, la reflexión sobre el independentismo y la extensión de una serie de paralelismos, definidores de lo cubano, de esa descripción

$111 \frac{\text { Revista Iberoamericana, Vol. LXXXV, Núm. 269, Octubre-Diciembre 2019, } 1311-1332}{\text { ISSN 2154-4794 (Electrónico) }}$ 
en varias generaciones siguientes, hasta la época contemporánea. Esas pautas que se repiten, en "la isla que se repite" (Benítez Rojo 15-46), son el exilio, la nefasta costumbre de la delación, la envidia que lleva a desear y procurar el mal al amigo o colega -idea desarrollada también en su artículo "Los horrores del mundo moral: los profesionales del odio" (Padura, Yo quisiera 270-73) a propósito de Domingo del Monte y José María Heredia-, la censura y la autocensura, el exilio y el universo de los dictadores (Esteban 316-35). Todo esto es cierto, pero muy pocos han reparado en el modo con el que Padura trata de ir más allá de una indagación sobre los ciclos de la historia cubana que condenan a la isla a un destino fatídico de repeticiones malditas. Pensamos que la novela explica a Cuba pero explica también el diálogo que establece la isla con todo el subcontinente en el periodo más importante de toda su historia: el paso del sistema colonial al republicano, a través del sangriento y complicado proceso de las independencias latinoamericanas. Las primeras décadas del siglo XIX son las que inauguran una conciencia de continente imposible de obtener durante los tres siglos de la Colonia, porque la pertenencia a España impedía los regionalismos, que ni siquiera coincidían con las divisiones virreinales, e impedía asimismo la mirada desde el interior en busca de una autodefinición continental. Las colonias eran España antes que América, del mismo modo que en el norte las colonias eran España, Francia, Inglaterra, Holanda, etc. La percepción eurocentrista de la situación de las "cuatro partes del mundo" proviene de una movilización a escala planetaria que impone el concepto de expansión(Gruzinski 52), lo que significa que los movimientos identitarios "oficiales" van siempre de Europa a América y no al revés. Solo en el siglo XIX esta situación experimenta un viraje, y aparece la obsesión por la identidad continental, desde el discurso de Bolívar hasta el de Martí, y la obsesión por las identidades nacionales. Lo paradójico -y eso se deja entrever en la novela de Padura- es que precisamente un lugar como Cuba, que no se independizará hasta el final del siglo, ofrece una de las visiones más completas y complejas del proceso alrededor de la figura de uno de los intelectuales, políticos y artistas más complejos y completos del XIX, José María Heredia. Su obra escrita y su labor política dan cuenta de que su estatura y su protagonismo en la historia del continente están a la altura de los próceres más celebrados, como sugiere José Antonio Portuondo:

Bello y Heredia son ejemplos eminentes de americanismo militante: ambos llevan su pasión creadora más allá de sus tierras nativas y se integran a la vida mexicana o chilena haciendo conciencias como antes Bolívar levantaba naciones. El movimiento independentista había esparcido escritores y guerreros por todo el continente, contribuyendo a propagar la esencial unidad ideológica latinoamericana, fundada en la básica identidad de sus problemas económicos, políticos y sociales [...]. Hay un afán desmedido por precisar las fronteras nacionales, mientras la letra común descubre la unidad de conciencia americana. (402)

$111 \frac{\text { Revista Iberoamericana, Vol. LXXXV, Núm. 269, Octubre-Diciembre 2019, } 1311-1332}{\text { ISSN 2154-4794 (Electrónico) }}$ 
Además, Heredia está unido a los independentistas latinoamericanos del momento por otro factor, no menos importante que el anterior: sufrió igualmente desencanto en la tarea que había comenzado a llevar a cabo. Podría ser que el suceso más sorprendente de la vida de Heredia, la carta que escribió a Tacón diciendo que se arrepentía de todo lo que había hecho, con el fin de que lo dejara entrar en la isla para ver morir a su madre, que ya agonizaba, no haya sido bien interpretado por los historiadores. Siempre se ha dado por supuesto que Heredia nunca se arrepintió de su pasado independentista, y que esa confesión tuvo el único fin de poder ver a su madre viva antes de su fallecimiento. Padura dedica una extensa sección a la conversación, que al comienzo tiene un interesante diálogo, sobre la base de algunas ironías de Tacón, el Capitán General y Gobernador de la isla, muy conocido por su férreo y tiránico ejercicio del poder:

- ¿Lo han tratado mal en Cuba? Mire que di órdenes estrictas...

-No, no, solo me han recordado que estoy aquí por su voluntad, y que su voluntad podía cambiar.

-Nada más lejos de mis deseos. Para mí era muy importante que usted viniera a Cuba. -Ya sé... Soy como un trofeo de guerra, ¿no?

-Usted siempre ha sido un mal ejemplo, y sus poemas... Heredia, que usted haya claudicado es una victoria para mi gobierno, para la corona española.

-Mi claudicación, como usted le llama, mucho tiene que ver con motivos personales.

-Sí, por supuesto. ¿Encontró bien a su señora madre?

-Afortunadamente.

-Cuánto me alegro... -y me miró directamente a los ojos--. Pero en su carta usted me hablaba de otras cosas. Me decía que ya no estima que lo mejor para esta isla sea la independencia.

-He visto lo que ha ocurrido en México. Se lo que sucede en Colombia, y no es alentador. -Eso se veía venir hace años. Yo llegué a América en 1809, como gobernador de Popayán, y sabía que todo terminaría así. (Padura, La novela 312)

Lo que el novelista recoge es la versión oficial de lo ocurrido en esos años treinta, pero no aclara si realmente Heredia estaba arrepentido de su independentismo anterior. La clave de este episodio y, en ese caso, también de la interpretación de la novela en un contexto continental en el que Heredia sería un "iniciador de caminos" (González Acosta 283-95), quizá nos la podría dar Rafael Rojas en su libro Las repúblicas de aire. Utopía y desencanto en la revolución de Hispanoamérica (2009). Heredia sería uno de esos ocho fundadores -letrados y estadistas- que intervinieron como verdaderos protagonistas en los procesos de independencia de América Latina. Los otros siete son los venezolanos Simón Bolívar y Andrés Bello, los mexicanos Fray Servando Teresa de Mier y Lorenzo de Zavala, el cubano Félix Varela, el peruano Manuel Lorenzo de Vidaurre y el ecuatoriano Vicente Rocafuerte. Pero hay otros próceres de las nuevas 
naciones que se relacionan con los anteriores en un mismo aspecto. Francisco Miranda, José de San Martín, José Artigas, Bernardo O’Higgins, Miguel Hidalgo y José María Morelos, entre otros, tuvieron cierto protagonismo en los primeros pasos de las nuevas repúblicas pero pronto dejaron de ser líderes, por diversas circunstancias, y engrosaron, como los ocho primeros, una larga lista de desencantados por el tenor que los gobiernos republicanos estaban imprimiendo a los países recién independizados. Poderes locales, caudillismo despótico, crisis económicas, ausencia de planteamientos democráticos, crímenes políticos de muy baja catadura, incapacidad para el diálogo y para aceptar las opiniones del pueblo o de las mayorías y corrupción generalizada, además de numerosas guerras civiles y entre los nuevos países, fueron los ingredientes de la historia de los años veinte y treinta del siglo XIX. En el caso de Heredia, no es de extrañar que, en verdad, él estuviera decepcionado de lo que estaba ocurriendo en México, donde participó activamente en la política del joven país, durante su largo exilio. Tanto Padura como Rojas parecen sugerirlo. La novela de Gabriel García Márquez dedicada a Bolívar, El general en su laberinto (1989), es uno de los textos más representativos y simbólicos de lo que constituyó el final de las guerras de independencia y el comienzo de las nuevas repúblicas. Aquel que fuera el líder más importante de los procesos revolucionarios terminó siendo un perseguido por sus propios adeptos, un hombre enfermo, decrépito, marginado, que se quedó fuera del juego del poder, y que pudo ver amargamente durante algún tiempo en qué habían quedado aquellas utopías de libertad, respeto, crisol pacífico de razas y culturas, que él y otros líderes habían procurado para la nueva andadura independiente del continente latinoamericano. El guiño de Padura al creador de Macondo es más que posible.

Pero Heredia no es solo uno de los símbolos de ese desencanto continental, que comparte decepción con las figuras más representativas de la época más importante de los cinco siglos de historia de América Latina; es también el primer romántico en el mundo hispánico, como afirmó Manuel Pedro González en su ensayo de rectificación histórica. Fue quien encendió la chispa del siglo literario. La centuria de la independencia fue también la del romanticismo, que se alargó hasta los últimos años del siglo, conviviendo con el modernismo y el naturalismo. En ninguna otra tradición literaria, ni siquiera en la alemana, el romanticismo duró tanto tiempo, y el tiempo político se unió al literario, o se acoplaron los dos, de un modo mucho más armónico que en otras zonas. En Alemania, por ejemplo, desde el Sturm und Drang hasta la unificación pasó un siglo. Sin embargo, en América Latina, la literatura de Bello y Bolívar fue paralela a las independencias, y el romanticismo quedó como testigo y como valedor, escrutador y guardián del proceso durante todo el XIX. Solo las segundas revoluciones, simbolizadas en la mexicana de 1910, que tenían como fin conseguir una segunda independencia, al decir de Martí, acabaron de verdad y de un modo definitivo con el espíritu del romanticismo y crearon una "vida moderna", que en lo literario se identificó con las vanguardias, mientras que Rubén Darío y su grupo

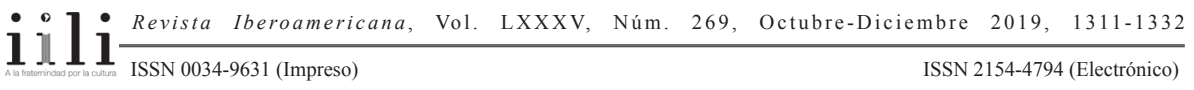


fueron el periodo de transición entre una época y la otra. Heredia, por lo tanto, se sitúa en los orígenes de ese proceso como un iniciador, piélago del que van a beber todas las fuentes de la modernidad.

Existe todavía una tercera vía que acumula méritos al cubano para establecerse como paradigma de lo que Cuba facilitó a occidente: su trayectoria en el exilio. Ya hemos hecho referencia a su protagonismo en el intento de sentar unas bases sólidas para la democracia en México, pero se debe aludir también a los frutos literarios de ese exilio. Sus dos obras más leídas, publicadas e imitadas son "En el Teocalli de Cholula" (1820) y la "Oda al Niágara" (1824): una habla de México y otra de los Estados Unidos. No son obras de estricta cubanía sino homenajes a lugares míticos de otros países. En la primera exalta la naturaleza y la vida de los aztecas, y eso puede interpretarse como uno de los primeros homenajes modernos al universo precolombino justo en el momento de las independencias, que miran al pasado para separarse de lo español y del lastre colonial. En la segunda, el propósito continental va más allá: Heredia exalta la naturaleza del primer país que lo ha acogido en su exilio: Estados Unidos. Junto con Félix Varela, que reside en Filadelfia y mantiene desde ahí una acción política combativa en pro de la independencia, Heredia ha podido participar en actividades literarias y políticas en esa zona del noreste del país, y ha tenido la oportunidad de conocer uno de los mitos de la naturaleza del mundo occidental: las cataratas del Niágara. Fascinado por el lugar pero fascinado también por la descripción que Chateaubriand había hecho del entorno en su novela Atala (1801), Heredia se convierte nuevamente en un iniciador de caminos, pues el Niágara llegará a ser en el siglo XIX y continuará siendo en el XX un símbolo de la belleza y de la fuerza de la naturaleza, y un lugar recurrente para poetas y artistas, que lo visitan y escriben sobre él. Son relevantes el drama de los mexicanos Riva Agüero y Mateos de 1862 La catarata del Niágara, el texto dedicado por el argentino Sarmiento en su libro Viajes, en el que no solo relata su admiración por el espectáculo de la naturaleza ("el pedazo más bello de la naturaleza", dijo) sino que constituye además una obra de profunda admiración por todo el país, en el que se quiso quedar y, como afirmó, hacerse "yankee"; el poema del romántico colombiano Rafael Pombo "En el Niágara", el relato del naturalista chileno Alberto Blest Gana "De Nueva York al Niágara", el poema de 1882 que le dedicó el venezolano Juan Antonio Pérez Bonalde, el extenso prólogo que escribió el mismo año Martí para el libro de Bonalde, verdadero manifiesto del modernismo, el libro de viajes del argentino Paul Groussac Del Plata al Niágara, la obra teatral del peruano Alonso Alegría, hijo de Ciro Alegría, El cruce sobre el Niágara, y un largo etcétera. El Niágara se convirtió, desde el romanticismo, en un lugar común en todo el territorio latinoamericano, tanto, que desde hace mucho tiempo se ha acuñado la frase "el Niágara en bicicleta" en Cuba y en la mayoría de los países latinoamericanos para significar que algo es muy difícil de conseguir.

La tercera novela de Padura que universaliza a Cuba y le confiere protagonismo 
es El hombre que amaba a los perros. Aparentemente, Cuba no tiene ninguna relación con los protagonistas: Ramón Mercader es un español integrado en la estructura del comunismo internacional prosoviético y Trotski un fugitivo ruso, errante de esa estructura, perseguido por Stalin, que acabó en México, acogido por la amabilidad y el compromiso de Cárdenas. Hay dos aspectos tremendamente llamativos y cruciales en la construcción técnica de esta novela, que destacan no por su novedad sino por su intensidad: el recurso a la historia y el dato escondido que desubica las tramas al comienzo pero que cierra el círculo al final y hace que todo cobre sentido. En la nueva andadura de los dos mil, la historia será siempre el eje de la presencia de Cuba en el mundo, como ya hemos visto. Con ello se suma el de Mantilla al auge del género de la novela histórica en los últimos veinte años, tanto en la literatura de más calidad como en la del best-seller. Como en las novelas anteriores, Cuba describe al mundo pero también el mundo describe a Cuba. La infamia del estalinismo en Rusia hace pensar en el estalinismo cubano, de igual modo que la tiranía de Tacón remitía directamente a la de Fidel Castro en la novela anterior. Las colectivizaciones de Stalin comenzaron en 1929, en el mismo momento en que se estaba desterrando y acosando a Trotski. Las que afectaron a Cuba comenzaron en la década de los sesenta y abolieron completamente la propiedad privada, que ha sido el factor decisivo en el empobrecimiento radical de la perla del Caribe. En una entrevista con Mauricio Vicent en El País, Padura enumeraba los males que había sufrido la isla desde la imposición del estalinismo:

La entronización de una burocracia siempre retardataria y cobarde; la eliminación de diversas formas de propiedad a favor de la estatal y la formación de un macro Estado que lo controla (o pretende) todo; la retórica; la verticalidad de las decisiones; la fusión de Estado, gobierno, partido único [...]. (“Cuba se merece vivir mejor” s/p)

En ese trueque de desgracias, imposiciones, desastres económicos y ausencia de libertad, que Cuba recibe de Stalin, la isla podrá ser nuevamente ejemplo y paradigma históricos. En una de las tres tramas que se cuentan, la más cercana a nuestro tiempo, Iván, el protagonista, coincide en Cuba con un hombre "que amaba a los perros", como Trotski, y entre los dos van sacando las conclusiones necesarias para entender la época negra del estalinismo pero también la época actual de la isla. Los paralelismos, cada vez más evidentes, de Mercader con ese hombre viejo, enigmático, que reside en Cuba, pero de un origen extranjero, mantienen en vilo al lector, que poco a poco va atando cabos. Que Cuba fuera el destino final de Mercader pone a la isla en el punto cenital de la historia del siglo XX: el hombre que mató a Trotski, el gran sacrificado de la Revolución rusa, por las veleidades del abuso de poder del asesino más sangriento de la historia de nuestra época, termina sus días en el contexto de la Revolución estalinista de Cuba, porque ni en la España franquista ni en la Rusia estalinista y posestalinista podría caber un individuo que cometió tal crimen. Pero esa conclusión se vuelve muy

$111 \frac{\text { Revista Iberoamericana, Vol. LXXXV, Núm. 269, Octubre-Diciembre 2019, } 1311-1332}{\text { ISSN 0034-9631 (Impreso) }}$ 
amarga cuando vamos uniendo, por detrás, otro tipo de cabos: el sistema y la desviación psicótica que arrastró a Mercader a integrarse en un proyecto de muertes masivas, corrupción y represión a escala continental, es decir, el proyecto de un pervertido y ególatra Stalin, tiene ciertos paralelismos, en una medida mucho menor, por el alcance político del líder, con lo que se está viviendo en la isla desde la llegada de otro ególatra obsesionado por el poder: Fidel Castro. Y es evidente que esa conclusión la debe sacar el lector, porque un cubano que reside en la isla jamás podría proponer claramente tal ecuación. De ahí el interés del cubano por esconder el mensaje en el envoltorio sutil de la técnica: confluencia de varias historias aparentemente dispares, que van uniéndose poco a poco, esfuerzos estructurales evidentes, claves estratégicamente reveladas en los momentos más decisivos de cada una de las historias, etc. En una entrevista de 2002, cuando Padura había decidido ya dar el giro hacia la universalización, como una manera de acometer más decisivamente un proyecto crítico contra la dictadura, afirmaba: "Cuando el escritor se encuentra frente a la decisión de lo que puede decir o de lo que no puede, los recursos artísticos son los que lo salvan" (Padura en Esteban 323).

El tema común podría ser el de la perversión de las utopías. Cuando Fidel Castro tomó el poder, gran parte de la población cubana pensó que por fin podría comenzar una nueva etapa de la historia no solo de Cuba, sino de toda América Latina y, quién sabe, del mundo occidental. Comenzaba la nueva utopía, que poco a poco se fue asimilando a la soviética, utopía que ya había dejado de serlo, a juzgar por la cantidad de desmanes que se habían producido en la etapa estalinista, quizá una de los peores ejemplos de bestialización de la humanidad, de conculcación de los derechos humanos y la dignidad más básica del habitante del globo terráqueo. La asunción del estilo del camarada Stalin y sus consecuencias en la población cubana fueron minando poco a poco la confianza del pueblo. Al final de la novela, Padura propone la reflexión sobre lo que ocurre cuando las utopías caen en el pozo de la perversión. Ya se ha analizado narrativamente la vida y la traición de Mercader, que se hizo pasar por trotskista y entabló una relación íntima con una trotskista cercana al desterrado en México, con el fin de tener acceso fácil al entorno de la víctima. Se ha analizado asimismo la vida y la maldad intrínseca de Stalin, para quien las vidas humanas, contadas por millones, eran solo peldaños sucesivos para satisfacer su paranoica obsesión por el poder. Se han puesto a la luz algunos de los problemas graves que atañen a la vida de los cubanos en la época actual, fruto de la aplicación de un sistema que recuerda bastante a lo reflejado en las historias anteriores $\mathrm{y}$, finalmente, todos los protagonistas han desaparecido de la escena. El amigo de Iván lo recuerda, después de su desaparición, revisa sus escritos y contempla cómo, a través de ellos, Iván representa a la masa, "a la multitud condenada al anonimato, y su personaje funciona también como metáfora de una generación y como prosaico resultado de una derrota histórica" (El hombre 569). En esa reflexión, el amigo de Iván se pregunta si todos aquellos protagonistas de la historia, incluido Trotski, que se creían nuevos mesías o pensaban que podían decidir por los

$111 \frac{\text { Revista Iberoamericana, Vol. LXXXV, Núm. 269, Octubre-Diciembre 2019, } 1311-1332}{\text { ISSN 2154-4794 (Electrónico) }}$ 
demás, o bien que los destinos colectivos justifican la subordinación de las personas individuales a la masa, eran capaces de entender la libertad. Esas interrogaciones son claves para entender el sentido final de la novela, y el papel del cubano medio, que con sus preguntas está cuestionando, o más bien condenando, las decisiones erradas de algunos que han destruido las vidas de millones de personas en todo el siglo XX a lo largo de los cinco continentes:

¿Y las personas, qué? ¿Alguno de ellos pensó alguna vez en las personas? ¿Me preguntaron a mí, le preguntaron a Iván, si estábamos conformes con posponer sueños, vida y todo lo demás hasta que se esfumaran (sueños, vida, y hasta el copón bendito) en el cansancio histórico y la utopía pervertida? (El hombre 570)

En varios lugares de la novela el narrador manda al carajo a Trotski por su fanatismo obcecado y su complejo ser histórico, que no creía en las tragedias personales, a pesar de la que él mismo vivió, sino solamente en los cambios de las etapas sociales y suprahumanas. La interpretación de la historia desde la base del marxismo anula la libertad individual y condena al hombre a ser arrastrado por las decisiones colectivas. Si estas son equivocadas (son siempre equivocadas), el hombre medio, mediano, mediocre, nada puede hacer contra el aparato del Estado, que decide por él hasta en los más mínimos detalles. En la nota de agradecimiento que sigue al final de la novela, Padura -y no el narrador- toma la palabra y revela las claves de la decisión de escribir sobre Trotski y la ideología que subyace a todos los regímenes comunistas (léase también Cuba):

Al enfrentarme a su concepción, más de quince años después, ya en el siglo XXI,
muerta y enterrada la URSS, quise utilizar la historia del asesinato de Trotski para
reflexionar sobre la perversión de la gran utopía del siglo XX, ese proceso en el que
muchos invirtieron sus esperanzas y tantos hemos perdido sueños, años y hasta sangre
y vida. Por eso me atuve con toda fidelidad posible [...] a los episodios y la cronología
de la vida de León Trotski en los años en que fue deportado, acosado y finalmente
asesinado. (El hombre 571)

En la novela Herejes se analiza otro de los grandes problemas de la historia del siglo XX. Si el exterminio estalinista fue el que más víctimas acarreó, el nazi no se quedó muy lejos. Y, nuevamente, en el centro de la reflexión sobre el problema de la diáspora judía, el racismo y la proyección en una gran zona de Europa de la locura, la ambición de poder y la ausencia total de respeto por la dignidad humana, la isla también se encuentra involucrada, esta vez por la llegada al puerto habanero de un barco cargado de judíos que escapaban del horror de la Alemania nazi. Pero la ambición de esta novela trasciende la misma historia contemporánea: desea ser un tratado sobre la libertad. Lo coyuntural no desaparece, se limita a ser metonimia de lo

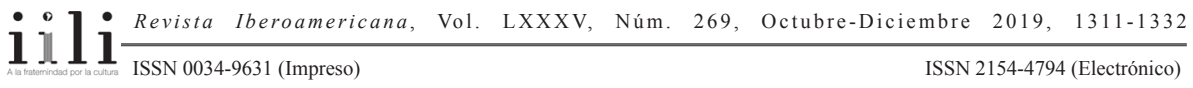


universal. Se trata, hasta el momento, de la culminación de un proyecto que comenzó, como venimos diciendo, al terminar la tetralogía de "Las cuatro estaciones". Nunca se desintegra lo cubano, pero queda asimilado y subsumido por las indagaciones en los recovecos más interiores de la misma naturaleza humana. Asegura Padura que una novela se escribe (eso lo dice para justificar el tema y el proceso de composición de Herejes) para "comprender la vida", pues todas las novelas "se alimentan de la naturaleza humana". ${ }^{3}$ Y continúa puntualizando que en la mayoría de las ocasiones, las novelas insisten en lo peor de esa condición: “el odio, la locura, el rencor, la exclusión del otro, la violencia, los fundamentalismos políticos o religiosos y, por supuesto, el placer de provocar miedo y el horror de sufrirlo" (Padura, La libertad 26). En el caso de Cuba y de América Latina - matiza-, los dos temas que más han preocupado a los escritores, también a él mismo, han sido la figura del dictador y las manifestaciones de violencia que han permeado la sociedad latinoamericana desde su fundación hasta el momento presente (La libertad 27).

En Herejes, además de estos dos temas, había una obsesión que se interconectaba con ellos:

la dosis de herejía que, en distintas sociedades, momentos históricos y vidas individuales podía revestir la pretensión de poner en práctica un libre ejercicio del albedrío individual, [o lo que es lo mismo], el natural deseo de ejercitar la libertad que $[. .$.$] solo los seres humanos tenemos la posibilidad y la capacidad de buscar$ conscientemente. (La libertad 5)

Esa obsesión nacía de haber sido una persona criada en un país socialista, donde el individuo se disipa y disuelve en el concepto de "masa". Aportando una experiencia muy cubana, millones de individuos de diversas épocas y naciones podrían sentirse identificados, ya que los estragos de los sistemas socialistas con la libertad han sido comunes, a la vez que penosos, en los últimos dos siglos de historia. Porque lo más importante de esa novela no iba a ser su adecuación a la historia "real", oficial (la tragedia del barco Saint Louis en las costas de La Habana en 1939, que tuvo que volverse a Alemania porque nadie concedió el permiso para desembarcar, o las peripecias de alguno de los cuadros más representativos de Rembrandt durante siglos), ni el protagonismo de Cuba en ciertos episodios cruciales de la historia contemporánea, relacionados con el exterminio provocado por el nazismo o la conservación del patrimonio cultural de

\footnotetext{
3 El texto de Padura donde aparecen estas palabras es La libertad como herejía. (Para qué se escribe una novela), alojado en https://cri.fiu.edu/news/2014/liberty-as-heresy-why-one-writes-novel-lecture-byleonardo-padura/la-libertad-como-herejia.pdf. Consultado el 5 de agosto de 2015. Existe una edición en e-book de este texto, publicada por Tusquets en enero de 2015, bajo el título La libertad como herejía. Apostillas a Herejes. Aquí citamos la edición de internet, ya que hasta el momento no existe copia en papel. La página concreta en la que aparecen estas palabras es la 26.
} 
la humanidad, sino la posibilidad de que las anécdotas de la Historia, contadas como una historia particular de una familia judía enraizada en La Habana, otra historia sobre la mala fortuna económica y social de Rembrandt en ciertas fases de su vida, otra sobre las andanzas de la familia de un cubano corrupto en la Venezuela de Chávez, y otra sobre un ex policía cubano reubicado en el negocio de la compraventa de libros, pudieran convertirse en reflexiones abstractas sobre la idea de la libertad. Al explicar Padura cómo se planteó presentar al joven cubano de familia judía que arrastraba el peso familiar de las consecuencias del fracaso del Saint Louis, apuntaba lo siguiente:

Si quería asomarme por encima de lo coyuntural y contingente, de lo doméstico y singular, debía levantar la mirada hacia un horizonte más abierto que la específica encrucijada cubana, y entregarle a mi pretensión una capacidad de funcionar en lo permanente y global. Fue al adquirir esa convicción cuando la persecutora obsesión me complicó la vida de la mejor manera de las posibles, pues me obligó a la ambición de universalizar el conflicto de ese joven cubano, para hacerlo históricamente trascendente y sacarlo de su coyuntura específica, pero sin que ese traslado perdiera su carácter típico que tanto me interesaba (el de un joven cubano de hoy), aunque conectándolo con un deseo (la libertad) que desde hace mucho acompaña al hombre. (La libertad 6)

En uno de los momentos más decisivos de la investigación de Mario Conde acerca de la desaparición de Judy, la hija del cubano corrupto con un pasado turbio en Venezuela, el ex policía conversa con la profesora de literatura de la chica, quien le cita un párrafo de una novela que Judy había comentado por escrito, donde hay un canto a la libertad mediante la crítica de los papeles, permisos, salvoconductos o pasaportes necesarios para moverse de un lugar a otro desde Cuba. Conde admite que el texto le es familiar, pero no recuerda el autor y la obra. Se establece entonces el siguiente diálogo:

-Ahora mismo... Me suena, pero no, no sé. -Conde se sintió superado.

-Carpentier. El siglo de las luces. Publicado en 1962...

-Parece que está escrito para ahora mismo.

-Está escrito para siempre. También para ahora mismo. Judy sabía para qué sirve la literatura... Porque agregó esto -dijo y volvió a leer-: "Si un país o un sistema no te permite elegir dónde quieres estar y vivir, es porque ha fracasado. La fidelidad por obligación es un fracaso". (Herejes 401-02)

Todos los personajes protagonistas que están conectados por el asunto principal de la trama (el cuadro de Rembrandt que pudo servir como salvoconducto para una familia judía que se encontraba en el Saint Louis) en diferentes espacios (La Habana, Londres, Países Bajos, Miami) y tiempos (la época de Rembrandt, todo el siglo XX y comienzos del XXI), tienen en común la búsqueda de la libertad, de la autenticidad, frente a las convenciones o las imposiciones políticas o religiosas. Es evidente que en

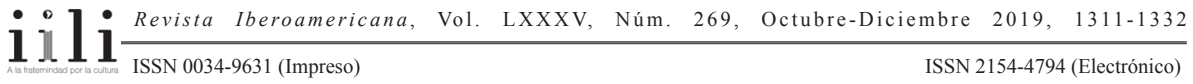


la superficie de la historia, o de las historias, llama la atención la crítica al holocausto y a la dictadura cubana, pero la mirada del autor va mucho más allá de lo coyuntural. La literatura, sobre todo la buena literatura, universaliza la anécdota, convierte en global lo local. Y no es casual que Padura haya elegido a Carpentier para elaborar la dialéctica de lo uno en lo diverso, pues el genio de las letras cubanas fue uno de los primeros en aludir a esa problemática, desde los años de la revista de vanguardia Avance y de su primera novela, ¡Écue-Yamba-Ó! (1933), en la que ya intentó elevar a la categoría de mito universal el contenido de las creencias y costumbres del mundo negro afrocubano. En el prólogo a una edición de 1977, Carpentier explicó lo difícil que fue llegar a una solución a comienzos de los treinta, pues las novelas de la época invitaban al localismo, al nacionalismo (las novelas de la tierra, regionalistas, como Doña Bárbara [1929], La vorágine [1924], Don Segundo Sombra [1926] y, en Cuba, las de Carrión o Loveira) mientras el espíritu de la vanguardia exigía la originalidad, el alejamiento de la tradición y el abrazo del cosmopolitismo cultural. Así lo recordaba: "Había, pues, que ser 'nacionalista', tratándose, a la vez, de ser 'vanguardista'. That's the question... Propósito difícil puesto que todo nacionalismo descansa en el culto a una tradición y el 'vanguardismo' significaba, por fuerza, una ruptura con la tradición" (Carpentier 153-54).

La etapa de mayor madurez de Carpentier, desde 1949 hasta sus últimas novelas, corrobora con plenitud lo que fue un experimento y un deseo en su primera obra. Y de eso sabe mucho Padura, que en 2002 publicó un extenso ensayo sobre la narrativa carpenteriana, en relación con el surrealismo y lo real maravilloso. En Herejes, Judy adopta la actitud de los emos para buscar la autenticidad, para librarse de las mentiras de su familia, para protestar contra la falta de libertad de un sistema político que la oprimey, en definitiva, para sentirse independiente y libre. Asimismo, Daniel Kaminsky, el muchacho judío cubano que no pudo ver nunca a sus familiares porque el Saint Louis desandó el camino, recorre varias veces el sendero del judaísmo al cristianismo y vice-versa, y el de la creencia al escepticismo, para tratar de explicarse el sentido de su historia pero también el sentido de la Historia y de la vida. El problema de la libertad, que ha sacudido el meollo de las investigaciones del ex policía, termina por instalarse en las entrañas del mismo Conde: la reflexión sobre los impulsos que llevaron a los investigados a tomar decisiones extremas, descubiertas por él, modelan poco a poco su existencia mediocre y escéptica. Cuando todos los datos sobre el cuadro, sobre la saga de cinco generaciones de los Kaminsky, sobre la desaparición de Judy y sobre el destino multisecular del cuadro de Rembrandt encajan como en un puzzle, lo único que queda es la reflexión. El narrador omnisciente detalla con sus palabras los pensamientos de Mario:

Solo vale la pena militar en la tribu que tú mismo has elegido libremente. Porque si cabe la posibilidad de que, de haber existido, incluso Dios haya muerto, y la certeza

$111 \frac{\text { Revista Iberoamericana, Vol. LXXXV, Núm. 269, Octubre-Diciembre 2019, } 1311-1332}{\text { ISSN 2154-4794 (Electrónico) }}$ 
de que tantos mesías hayan terminado convirtiéndose en manipuladores, lo único que te queda, lo único que en realidad te pertenece, es tu libertad de elección. Para vender un cuadro o donarlo a un museo. Para pertenecer o dejar de pertenecer. Para creer o no creer. Incluso, para vivir o para morirte. (Herejes 513)

La vida personal del ex policía se parecía mucho a todas esas historias de otros que él trataba de poner de pie. Su relación con Tamara, intermitente y sin demasiados compromisos, estaba a punto de acabar en matrimonio. Ya le había comprado el anillo y se lo había entregado. Sin embargo, algo le impelía a no dar el paso definitivo, a no estableceruna relación "contractual", además de la sentimental. Conde necesitaba sentirse libre, y el matrimonio podría, quizá, establecer un nudo de implicaciones perjudiciales para lo que, hasta el momento, había sido esa relación. Así lo insinúa el narrador:

Una vez que la mujer se convirtiera en su esposa la relación sufriría la merma de una de las pocas cosas que todavía le pertenecían: su libertad. La de emborracharse o no, compartir la cama con un perro callejero, comprar o no comprar libros, morirse de hambre o comer, no decidirse a escribir, vivir como un paria, ponerse melancólico sin necesidad de darle explicaciones a nadie..., hasta invertir su tiempo buscando a una emo que a su vez andaba en busca de un Dios resucitado y, al parecer, tenía esperanzas de encontrarlo. (Herejes 485-86)

Esa misma disyuntiva es la que plantea en la película Regreso a Ítaca (2014), basada en una de las líneas argumentales de La novela de mi vida, con un guion adaptado por el mismísimo protagonista, que se encuentran en una terraza de La Habana, después de que uno de ellos haya pasado más de quince años fuera de Cuba, malviviendo en España, relatan sus respectivas vidas durante ese periodo, airean su particular lista de agravios y piden explicaciones por conductas que, aparentemente, tienen poca justificación. Poco a poco, cada uno da cuenta de lo que ha sido su uso de la libertad, y las consecuencias de ese uso, en un contexto de un régimen político autoritario que les ha dejado poco margen de maniobra. Solo hay un ingrediente en esta película que se añade al panorama existencial de Herejes: el miedo. Los cinco protagonistas confiesan en algún momento del diálogo que, si algo ha definido sus decisiones, ha sido el miedo, un factor que regula, tantas veces desde la inconsciencia, los vericuetos de la libertad. De ese modo, el escritor cubano logra una vez más universalizar un tema muy específico de la cultura de la perla del Caribe, para convertirlo en una indagación sobre la naturaleza humana. De ese modo, lo que Cuba puede ofrecer al mundo occidental no solo tiene que ver con los temas en los que Padura ha incursionado en sus novelas del siglo XXI, que delimitan los contornos de un flujo de relaciones del Caribe hacia el resto de América y hacia Europa, sino una tensión existencial en la que puede verse retratado cualquier ser humano, como en las preguntas universales de Hamlet, Don Quijote o la Biblia.

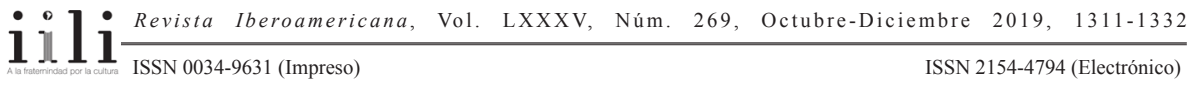


Hay todavía una reflexión más acerca del juego que se establece en el espacio entre lo local y lo global, lo personal y lo universal, lo nacional y lo cosmopolita. En la película Regreso a Ítaca, Amadeo, el exiliado que acaba de llegar a La Habana, asegura que ha vuelto, entre otras razones, porque no ha podido escribir desde que se fue. Necesita estar en Cuba para continuar su carrera literaria, interrumpida durante los dieciseis años de exilio. Del mismo modo, Leonardo Padura ha continuado viviendo no solo en Cuba, sino en el mismo barrio a las afueras de La Habana y en la misma casa de siempre. El cubano, que posee también la nacionalidad española desde hace años, que tiene una situación económica desahogada y que podría vivir “mejor” en otros países, nunca ha pensado en trasladarse a otro lugar. Padura es muy crítico con la ausencia de libertad en Cuba, con la dictadura, con los problemas económicos, pero ha decidido continuar en la isla porque, además de sentirse muy cubano y estar apegado a sus raíces, necesita vivir, sentir lo cubano a diario para escribir sus obras, tanto las estrictamente cubanas de los noventa como las que en el nuevo siglo combinan la cubanía con la apertura al mundo occidental. Cuba será siempre la base de sus creaciones, porque su narrativa es siempre experiencial. Padura inventa sobre lo vivido o lo conocido; por eso, a la materia de lo cubano sentido y entendido en primera persona, siempre añade los herrajes de una profunda investigación histórica, literaria, geográfica, artística, de unas épocas y lugares determinados, como corresponde a su formación universitaria, a la ansiedad por la pesquisa y el rigor académico. El resultado es una impresión absoluta de verosimilitud. Creer en lo que dicen las novelas de Padura no es difícil: las preguntas básicas sobre la existencia humana están arraigadas en un modelo de historias en las que los personajes son hombres y mujeres con vidas corrientes, grandes derrotados con sus virtudes y sus vicios, héroes mediocres que sienten lo mismo que los hombres y mujeres que pueblan la faz de la tierra. 
Bajtín, Mijail. Teoría y estética de la novela. Madrid: Taurus, 1989.

Benítez Rojo, Antonio. La isla que se repite. Barcelona: Casiopea, 1998.

Carpentier, Alejo. ¡Écue-Yamba-Ó!. Madrid: Akal, 2010.

Castro, Fidel. "Discuros de clausura del Primer Congreso Nacional de Educación y Cultura". Teatro de la CTC. 30 abril 1971. <http://www.cuba.cu/gobierno/ discursos/1971/esp/f300471e.html>. 19 mayo 2015.

Esteban, Ángel. Literatura cubana entre el viejo y el mar. Sevilla: Renacimiento, 2006.

García Márquez, Gabriel. El general en su laberinto. Bogotá: Editorial Oveja Negra, 1989.

González, Manuel Pedro. José María Heredia, primogénito del romanticismo hispánico: ensayo de rectificación histórica. México: Colegio de México, 1955.

González Acosta, Alejandro. "Heredia: iniciador de caminos". Encuentro de la Cultura Cubana 26/27 (2002-2003): 283-95.

Gruzinski, Serge. Las cuatro partes del mundo. Historia de una mundialización. México: Fondo de Cultura Económica, 2000.

Hemingway, Ernest. El viejo y el mar. Barcelona: Planeta, 1975.

Lezama Lima, José, Ángel Esteban y Álvaro Salvador, eds. Antología de la poesía cubana. 4 vols. Madrid: Verbum, 2002.

Martí, José. "Nuestra América”. Obras completas. La Habana: Editorial de Ciencias Sociales, 1975.

Padura, Leonardo. Adiós, Hemingway. Barcelona: Tusquets, 2006.

El camino de medio siglo: Alejo Carpentier y la narrativa de lo real maravilloso. México: Fondo de Cultura Económica, 2002.

La cola de la serpiente. Vol. 90/7. Barcelona: Tusquets Editores, 2011.

Fiebre de caballos. Madrid: Verbum, 2014.

Herejes. Barcelona: Tusquets, 2013.

El hombre que amaba a los perros. Barcelona: Tusquets, 2009.

La libertad como herejía. (Para qué se escribe una novela). 2014. <https://cri. fiu.edu/news/2014/liberty-as-heresy-why-one-writes-novel-lecture-by-leonardopadura/la-libertad-como-herejia.pdf $>$. 5 agosto 2015.

La neblina de ayer. Vol. 577. Barcelona: Tusquets Editores, 2005.

La novela de mi vida. Barcelona: Tusquets, 2002.

Paisaje de otoño. La Habana: Ediciones Unión, Unión de Escritores y Artistas de Cuba, 1999.

Yo quisiera ser Paul Auster. Ensayos selectos. Madrid: Verbum, 2015.

Ponce, Néstor. "Historia, memoria, policial en La neblina del ayer". Espéculo 47 (2011). <http://www.ucm.es/info/especulo/numero47/neblina.html>. 5 agosto 2015.

$111 \frac{\text { Revista Iberoamericana, Vol. LXXXV, Núm. 269, Octubre-Diciembre 2019, } 1311-1332}{\text { ISSN 0034-9631 (Impreso) }}$ 
Portuondo, José Antonio. "Literatura y sociedad". América Latina en su literatura. César Fernández Moreno, ed. México: Siglo XXI, 1988. 391-405.

Rojas, Rafael. Las repúblicas de aire. Utopía y desencanto en la revolución de Hispanoamérica. Madrid: Taurus, 2009.

Vicent, Mauricio. "Cuba se merece vivir mejor (entrevista a Leonardo Padura)". El Pais, 12 feb. 2011. <http://cultura.elpais.com/cultura/2011/02/12/ actualidad/1297465205_850215.html>.9 junio 2015.

Palabras clave: Leonardo Padura - genealogía literaria - crítica social cubana intertextualidad - universalismo

Recibido: $\quad$ agosto 2016

Aceptado: $\quad$ mayo 2017 